\begin{tabular}{c}
\hline Review of \\
ECONOMICS \\
and \\
INSTITUTIONS
\end{tabular}

Review of Economics and Institutions ISSN 2038-1379 DOI:10.5202/rei.v8i2.243

Vol. 8 - No. 2, Fall-Winter 2017 - Article 2

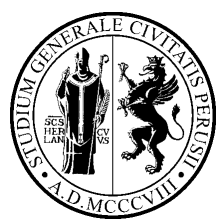

www.rei.unipg.it

\title{
VAT Evasion in Bulgaria: A General-Equilibrium Approach
}

\author{
Aleksandar Vasilev ${ }^{\bowtie}$ \\ Independent Researcher
}

\begin{abstract}
This paper utilizes an otherwise standard micro-founded general-equilibrium setup, which is augmented with a revenue-extraction mechanism to assess the magnitude of VAT evasion. The model is calibrated to Bulgaria after the introduction of the currency board (1999-2014), as one of the very few countries in Europe with a nondifferentiated consumption tax rate, and an economy where VAT revenue makes almost half of total government tax revenue. A computational experiment performed within this setup estimates that on average, the size of evaded VAT is a bit more than onefourth of output, an estimate which is in line with the figures provided in both Philip (2014) and the European Commission (2014). In addition, model-based simulations suggest that increases in spending on law and order could generate substantial welfare gains by decreasing VAT evasion.
\end{abstract}

JEL classification: D58, E26, H26, K42

Keywords: VAT evasion; general equilibrium; Bulgaria

Email: alvasilev@yahoo.com.

\section{Recommended Citation}

Vasilev, A., (2017). VAT Evasion in Bulgaria: A General-Equilibrium. Review of Economics and Institutions, 8(2), Article 2. doi: 10.5202/rei.v8i2.243.

Retrieved from http://www.rei.unipg.it/rei/article/view/243

Copyright $(\subset 2017$ University of Perugia Electronic Press. All rights reserved 


\section{Introduction and Motivation}

After the fall of the communist regime in 1989, Bulgaria had to reform its tax system to reflect the new market reality. Both its historical heritage, and the European spirit of solidarity led to the adoption of a public finance model that emphasized consumption-based taxation. In what is to follow, "consumption tax" an "VAT" will be used interchangeably. Income taxation in Bulgaria was of much smaller importance for the budget: for example, over the period 2007-2014, taxation of individuals constitutes 9-11\% of overall tax revenue. Yet another reason was the absence of sufficiently qualified tax administration in the early 1990s. The dynamics of the share of VAT revenue in total tax revenue in Bulgaria is presented in Figure 1.

\section{Figure 1 - Fiscal Importance of VAT Revenue in Bulgaria (1997-2012)}

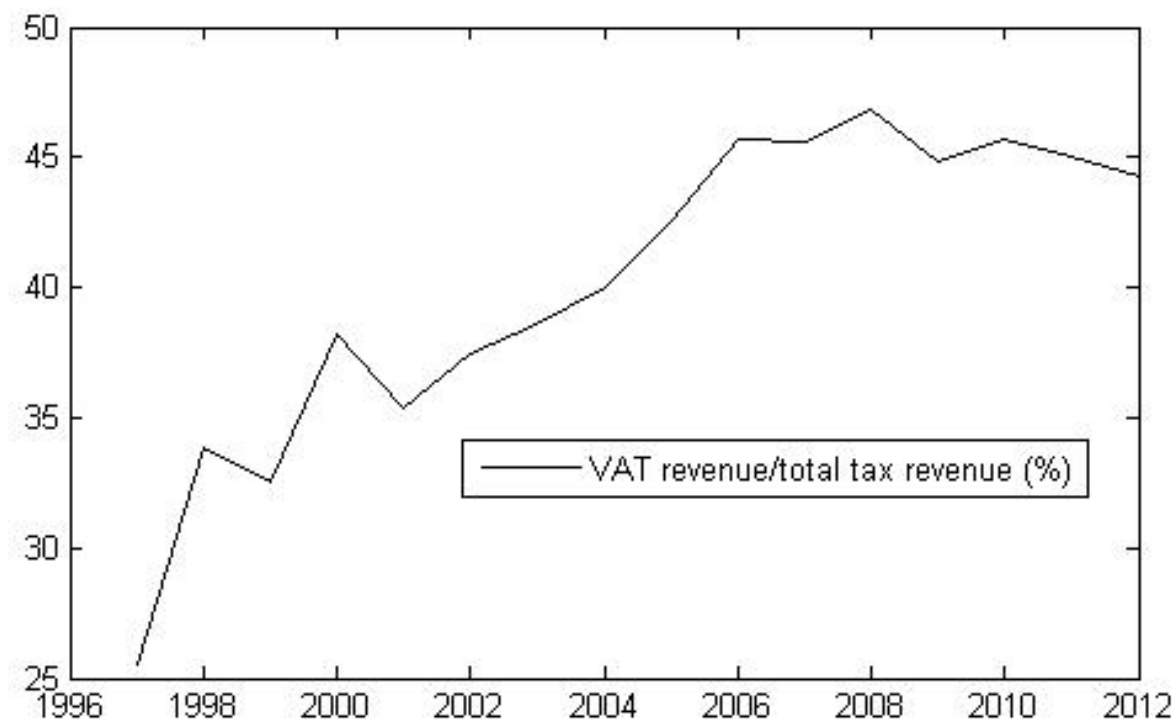

Source: WDI (2015)

As seen from Figure 1 above, VAT revenue is the major source of tax revenue in Bulgaria (and most of Central and Eastern Europe, for that matter). VAT as a share in total tax revenue increased in importance after its introduction and implementation in 1994 from $25 \%$ of total tax revenue to $35 \%$ in the years following the currency board implementation (in 1997), where the increase was due to the macroeconomic stability that was achieved by fixing the Bulgarian lev (BGN) to the German mark at parity. Post-1997, the share of VAT revenue in total government revenue increased further until it leveled off at approximately $45 \%$ of total tax revenue after Bulgaria's EU accession in 2007, and the subsequent income tax reforms that followed the introduction of $10 \%$ proportional (flat) tax rate on both corporate profit, and individual income, as of 2007 and 2008, respectively. 
Since the VAT revenue makes almost half of total tax revenue in Bulgaria, most of the tax collection problems are associated with this category, especially after the substantial simplification of the income tax code and the sizable decrease in the income tax rates, both on corporate profit and individual income, as of 2007 and 2008, respectively. $\left.\right|^{1}$ The term used by fiscal authority is called the "VAT gap," which is defined as the difference between the expected VAT revenue less the VAT actually collected by tax authorities. This "VAT gap", or the size of the evaded VAT, is what this paper aims to assess, and where the major contribution of the study lies. This paper uses modern quantitative macroeconomic theory to estimate the size of the loss from the VAT evasion at aggregate level, and we focus on the period following the introduction of the currency board. ${ }^{2}$ The setup in this paper is a relatively standard micro-founded general-equilibrium framework populated by a unit mass of households and augmented with a revenueextraction mechanism as in Vasilev (2017). Similarly to Angelopoulos et al. $(2009,2011)$, each one-member household can decide to spend working time on rent-seeking activities and try to hide (or equivalently, "extract") part of the VAT revenue from the government. To the best of our knowledge, no such setup, explicitly focusing on VAT evasion, exists for transition and/or development countries. Using models that are disciplined by both theory and data are useful tools to inform policy makers on issues, whose effects are otherwise hard to measure. After all, model-based estimates of the losses associated with VAT fraud for transition and developing countries, based on optimal behavior, are missing from the public finance literature. Lastly, the study in this paper could be also relevant for Eastern European countries considering EU accession (Albania, Serbia, Montenegro, Former Yugoslav Republic of Macedonia-FYROM) and ones that generate most of the tax revenue in the form of trade and border taxes, e.g. Kosovo.

Furthermore, the study adds value to an older literature, the Computable General Equilibrium (CGE) literature, e.g., as represented by the work in de Melo et al. (1992), who computes a model for Madagascar, and also find substantial losses from VAT evasion. However, in contrast to the CGE literature, our model belongs to the much more modern literature, the Dynamic General Equilibrium (DGE) class of models, which, in contrast to the static ad hoc CGE models, are micro-founded and deeply rooted in optimization. VAT evasion in this paper arises as a conscious choice made by individuals, who compare the benefits and the costs of engaging in tax fraud. Our study also differs in important ways from Angelopoulos et al. (2009), who use a

1 In another line of research, as shown in Vasilev (2015a), the move from progressive to proportional taxation of income has significantly decreased the size of the grey economy in Bulgaria.

2 For simplicity and better model tractability, the setup presented in this paper will abstract away from excise taxes, such as taxes on tobacco, alcohol, fuel, and gambling. Nevertheless, the model still captures smuggling and contraband, as cigarettes and fuel are both levied with the VAT, and with the excise tax. 
similar model to focus on overall tax evasion and the cost of rent-seeking in EU-12 member states in the form of captured "income transfers, subsidies and preferential tax treatment." In contrast, the present study focuses on the "sales tax" evasion aspect of VAT evasion, which is connected to the interaction between retail sellers and buyers.

Yet another strand of literature that our paper adds value to are microsimulation studies of the macroeconomic effects of consumption tax reform in Western Europe: Kehoe et al. (1988) focuses on the VAT reform in Spain from 1986, while Alvarez-Martinez and Polo (2014) focus on tax reforms in Spain during the Great Depression; a very recent study by Bye et al. (2015) discusses the VAT reform in Norway. However, Bulgaria (as well as Albania and Croatia) is a particular case in the EU, since its VAT rate is nondifferentiated, and all consumption goods are levied with the same rate. Thus, most of the studies on Western European countries are of very limited relevance to the research in this paper.

The rest of the paper is organized as follows: Section 2 describes the model setup, Section 3 describes the model calibration, Section 4 characterizes the symmetric steady-state, Section 5 evaluates the welfare effects of some institutional reforms, and Section 6 discusses some of the model assumptions and limitations. Section 7 concludes.

\section{Model Description}

There is a unit mass of households who derive utility out of consumption, leisure and public services. The time available to households can be spent in productive or in activities leading to VAT evasion. The benefit from opportunistic behavior is measured in terms of the share of extracted VAT payments. Thus, the government is not able to collect all the tax revenue, and will spend less on utility-enhancing public purchases and government transfers. On the production side, there is a representative firm, which produces a homogeneous final good, which could be used for consumption, investment, or government purchases.

\subsection{Households}

There is a unit mass of one-member households, indexed by $i$. Each household $i$ maximizes its utility function:

$$
\sum_{t=0}^{\infty} \beta^{t}\left\{\ln c_{i t}+\gamma \ln \left[1-h_{i t}\right]+\ln g_{t}^{c}\right\},
$$

where $c_{i t}$ denotes household's $i$ private consumption in period $t, h_{i t}$ are non-leisure hours in period $t, g_{t}^{c}$ is per-household consumption of public services, $0<\beta<1$ is the discount factor, and $\gamma>0$ is the relative weight that each household attaches to leisure. 
Each household $i$ starts with an initial stock of physical capital $k_{i 0}$, and has to decide how much to add to it in the form of new investment. Every period physical capital depreciates at a rate $\delta, 0<\delta<1$. The law of motion for physical capital is then

$$
k_{i, t+1}=i_{i t}+(1-\delta) k_{i t},
$$

and the real interest rate is $r_{t}$, hence the before-tax capital income of household $i$ in period $t$ equals $r_{t} k_{i t}$.

In addition to capital income, each household can generate labor income. However, not all hours are spent in productive activities: only $\eta_{i t}$ share, $0<$ $\eta_{i t}<1$, is dedicated to working in the representative firm, where the hourly wage rate is $w_{t}$, so labor income equals $w_{t} \eta_{i t} h_{i t}$. The remaining hours, $(1-$ $\left.\eta_{i t}\right) h_{i t}$, are used to engage in activities, whose aim is to evade paying VAT taxes. ${ }^{3}$ The reward from engaging in VAT evasion is that the household can capture a share of the lost aggregate VAT tax revenue from the government, and thus augment its income. The "prize," or the rent, obtained as a result of the opportunistic behavior, $R_{i t}$, is represented by the following technology, which is akin to the one used in Angelopoulos et al. $(2009,2011)$ :

$$
R_{i t}=\theta \tau^{c} C_{t} \frac{\left(1-\eta_{i t}\right) h_{i t}}{\sum_{i}\left(1-\eta_{i t}\right) h_{i t}},
$$

where $\tau^{c}$ is the VAT/consumption tax rate, $C_{t}$ denotes aggregate consumption, and $\tau^{c} C_{t}$ represents total VAT revenue in period $t$. Since the individual household is assumed to be small relative to the aggregate, $C_{t}$ is taken as given. Parameter $\theta, 0<\theta<1$, is the efficiency of the rent-seeking technology) while $\frac{\left(1-\eta_{i t}\right) h_{i t}}{\sum_{i}\left(1-\eta_{i t}\right) h_{i t}}$ is the endogenous probability of winning the "prize" (or getting a larger per-household "slice" of the rent pie). This probability is positively related to the own time spent evading taxes, and negatively related to the time other households' spend in tax evasion. In other words, every period each household will be playing the non-cooperative Nash equilibrium strategy against other households in a repeated strategic setup. Every household, taking the time rent seeking by its opponents as given, dedicates time resource to increase its slice (or the chance of winning). This optimality condition holds true for any household. At the end, the Nash equilibrium will be described as a situation when each household's best response is a best response to the other households' best responses.

The rent is determined to depend on aggregate, rather than simply on individual consumption, since some individuals might own larger companies that would extract much more than a quantity proportional to one's individual consumption: In Bulgaria, as in many other (Eastern) European countries, it is the retail merchant who is obliged by law to transfer the tax owed

3 One example of such activity would represent the opening of an "empty" firm with no activity, so that all expenses are registered as investment goods (and thus exempt of VAT), while in fact they are used for consumption purposes. 
to the tax revenue agency, since firms are owned by individuals, assuming that individuals directly evade the VAT (or through firm ownership) in the model is a useful simplification, which does not decrease the contribution of the paper, or affect the main results of the study in any major way: ${ }^{4}$

Next, household $i$ 's problem can be now simplified to

$$
\max _{\left\{c_{t}, \eta_{t}, h_{t}, k_{t+1}\right\}_{t=0}^{\infty}} \sum_{t=0}^{\infty} \beta^{t}\left\{\ln c_{i t}+\gamma \ln \left[1-\left(1-\eta_{i t}\right) h_{i t}-\eta_{i t} h_{i t}\right]+\ln g_{t}^{c}\right\}
$$

s.t.

$$
\left(1+\tau^{c}\right) c_{i t}+k_{i, t+1}-(1-\delta) k_{i t}=\left(1-\tau^{y}\right)\left[w_{t} \eta_{i t} h_{i t}+r_{t} k_{i t}+\pi\right]+g_{i t}^{t}+\theta \tau^{c} C_{t} \frac{\left(1-\eta_{i t}\right) h_{i t}}{\sum_{i}\left(1-\eta_{i t}\right) h_{i t}},
$$

where $\tau^{y}$ is the proportional income tax rate $\left(0<\tau^{y}<1\right)$, levied on both labor and capital income, $\pi$ denotes household $i$ 's profit income, and $g_{i t}^{t}$ is household $i$ 's government transfer. The problem generates the following optimality conditions:

$$
\begin{aligned}
c_{i t} & : \frac{1}{c_{i t}}=\lambda_{t}\left(1+\tau^{c}\right) \\
k_{i, t+1} & : \lambda_{t}=\beta \lambda_{t+1}\left[1+\left(1-\tau^{y}\right) r_{t+1}-\delta\right] \\
\eta_{i t} h_{i t} & : \frac{\gamma}{1-h_{i t}}=\lambda_{t}\left(1-\tau^{y}\right) w_{t} \\
\left(1-\eta_{i t}\right) h_{i t} & : \frac{\gamma}{1-h_{i t}}=\lambda_{t} \theta \tau^{c} C_{t} \frac{1}{\sum_{i}\left(1-\eta_{i t}\right) h_{i t}} \\
T V C & : \lim _{t \rightarrow \infty} \beta^{t} \lambda_{t} K_{t+1}=0,
\end{aligned}
$$

where $K_{t}$ denotes aggregate physical capital in period $t$, and $\lambda_{t}$ is the Lagrangean multiplier attached to household $i$ 's budget constraint in period $t$.

The interpretation of the first-order conditions above is standard: the first one states that for each household, the marginal utility of consumption equals the marginal utility of wealth, corrected for the consumption tax rate. The second equation is the so-called "Euler condition," which describes how each household chooses to allocate physical capital over time. Next, at the margin, each hour spent working for the firm should balance the benefit from doing so in terms of additional income generates, and the cost measured in terms of lower utility of leisure. Similarly, at the margin, an hour spent rent-seeking should equate the benefit (in terms of captured VAT revenue) and the utility cost. The last condition is called the "transversality condition" (TVC): it states that at the end of the horizon, the value of physical capital should be zero.

4 The shortcut taken in this paper is also useful, as it might be viewed as an approach that captures the collusion between individuals and tax officers, as big VAT evasion schemes usually have an inside help and protection in the face of politicians, tax inspectors, customs officials, and/or police officers. 


\subsection{Firm}

There is a representative firm in the economy, which produces a homogeneous product. The price of output is normalized to unity. The production technology is Cobb-Douglas and uses both physical capital, $k^{f}$, and labor hours, $h^{f}$, to maximize static profit

$$
\Pi_{t}=A\left(k_{t}^{f}\right)^{\alpha}\left(h_{t}^{f}\right)^{1-\alpha}-r_{t} k_{t}^{f}-w_{t} h_{t}^{f},
$$

where $A$ denotes the level of technology. Since the firm rents the capital from households, the problem of the firm is a sequence of static profit maximizing problems. In equilibrium, there are no profits, and each input is priced according to its marginal product, i.e.:

$$
\begin{aligned}
& k_{t}^{f}: \alpha \frac{y_{t}}{k_{t}^{f}}=r_{t}, \\
& h_{t}^{f}:(1-\alpha) \frac{y_{t}}{h_{t}^{f}}=w_{t} .
\end{aligned}
$$

\subsection{Government}

In the model setup, the government is levying taxes on labor and capital income, as well as consumption in order to finance spending on utilityenhancing government purchases. However, due to VAT evasion (which could be due to inefficiencies in the way tax officials operate), the government is able to collect only $1-\theta$ share of the consumption tax revenue. The government budget constraint is as follows:

$$
g_{t}^{c}+\sum_{i} g_{i t}^{t}=(1-\theta) \tau^{c} \sum_{i} c_{i t}+\tau^{y}\left[w_{t} \sum_{i} \eta_{i t} h_{i t}+r_{t} \sum_{i} k_{i t}\right]
$$

Government consumption-to-output ratio would be obtained from the market clearing condition (resource constraint), and government transfers would be determined residually in each period so that the government budget is always balanced.

\subsection{Market Clearing}

In addition to the optimality conditions from the household's and firm's problem, as presented in the previous subsections, and the government budget constraint above, we need to impose consistency among the different decisions. More specifically, this would require that in equilibrium (i) aggregate quantities equal the sum of individual allocations, and (ii) output, capital and labor markets all clear, or for all $t$ :

$$
\sum_{i}\left[c_{i t}+k_{i, t+1}-(1-\delta) k_{i t}\right]+g_{t}^{c}=y_{t}
$$




$$
\begin{aligned}
\sum_{i} c_{i t} & =C_{t} \\
\sum_{i} g_{i t}^{t} & =g_{t}^{t} \\
\sum_{i} k_{i t}=k_{t}^{f} & =K_{t} \\
\sum_{i} \eta_{i t} h_{i t} & =h_{t}^{f} .
\end{aligned}
$$

\subsection{Dynamic Competitive Equilibrium (DCE)}

For a given level of technology $A$, average tax rates $\left\{\tau^{c}, \tau^{y}\right\}$, initial individual capital endowments stock $k_{i 0}, \forall i$, and aggregate allocations $\left\{C_{t}, K_{t}\right\}_{t=0}^{\infty}$, the decentralized dynamic competitive equilibrium is a list of sequences $\left\{c_{i t}, i_{i t}, k_{i t}, \eta_{i t}, h_{i t}\right\}_{t=0}^{\infty}$ for each household $i$, input levels $\left\{k_{t}^{f}, h_{t}^{f}\right\}$ chosen by the firm in each time period $t$, a sequence of government purchases and transfers $\left\{g_{t}^{c}, g_{t}^{t}\right\}_{t=0}^{\infty}$, and input prices $\left\{w_{t}, r_{t}\right\}_{t=0}^{\infty}$ such that (i) each household $i$ maximizes its utility function subject to its budget constraint; (ii) the representative firm maximizes profit; (iii) government budget is balanced in each period; (iv) all markets clear.

\subsubsection{Symmetric DCE}

In the general, non-symmetric, case it is very difficult to solve the system defined in the subsection above. More specifically, the model in its general formulation can generate a multitude of distributions of capital stock holdings across households, and in this sense, the equilibrium is indeterminate. Therefore, we will concentrate on a particular equilibrium, one in which all households are identical, or the symmetric solution. This requires setting $k_{i 0}=k_{0}$, and imposing symmetry in the DCE system for all $i$, which in turn greatly simplifies the optimality conditions derived above. Since the model features a unit mass of households, this produces $c_{i t}=C_{t}, k_{i t}=K_{t}, h_{i t}=$ $h_{t}, \eta_{i t}=\eta_{t}$, etc. In addition, in the symmetric equilibrium every household will receive an equal share of the pie, or the rent from VAT evasion will be spread uniformly (note that total rent is now $R_{t}=\theta \tau^{c} C_{t}$ ). Indeed, this might be a shortcoming of the setup, but since the main objective is to make a prediction about the aggregate size of the VAT extracted, not how the degree of evasion is distributed across the population, the focus on the symmetric DCE is not a significant limitation of the analysis.

\section{Data and Model Calibration}

To compute the size of VAT evasion in Bulgaria, we will focus on the period after the introduction of the currency board (1999-2014). Data on output, consumption and investment was collected from National Statisti- 
cal Institute (2015), while the real interest rate is taken from Bulgarian National Bank Statistical Database (2015). The calibration strategy described in this section follows a long-established tradition in modern macroeconomics: first, the discount factor, $\beta=0.937$, is set to match the steady-state capitalto-output ratio in Bulgaria, $k / y=3.491$, in the steady-state consumptionEuler equation (7). The labor share parameter, $\alpha=0.429$, was obtained as the average value of labor income in aggregate output over the period 1999-2014. This value is slightly higher as compared to other studies on developed economies, due to the overaccumulation of physical capital, which was part of the ideology of the totalitarian regime, which was in place until 1989.

The relative weight attached to the utility out of leisure in the household's utility function, $\gamma$, is calibrated to match that in steady-state consumers would supply one-third of their time endowment to working. This is in line with the estimates for Bulgaria as well over the period studied. The depreciation rate of physical capital in Bulgaria, $\delta=0.05$, was taken from Vasilev (2015b). It was estimated as the average depreciation rate over the period 1999-2014. Due to the lack of additional information, the share of working time used productively, $\eta=2 / 3$, was set as in Angelopoulos et al. (2011) from his study on Mexico. Alternatively, the share of working time used in the VAT evasion technology, $1-\eta=1 / 3$, could be pinned down as the average hidden employment share as estimated by Center for the Study of Democracy (2015). In other words, one third of the working time in Bulgaria is assumed to be spent evading taxes. With its help, the value of $\theta$, the share of VAT tax evasion out of total consumption tax revenue, can be then calibrated $\sqrt[5]{5}$ Finally, the average income tax rate was set to $\tau^{y}=0.1$. This is the average effective tax rate on income between 1999-2007, when Bulgaria used progressive income taxation, and equal to the proportional income tax rate introduced as of 2008. Finally, the tax rate on consumption is set to its value over the period, $\tau^{c}=0.2$. Table 1 below summarizes the values of all model parameters used in the paper.

\section{Steady-state}

Once the values of model parameters were obtained, the steady-state equilibrium system solved, the "big ratios" can be compared to their averages in Bulgarian data. The results are reported in Table 2 on the next page. The steady-state level of output was normalized to unity (hence the level of technology $A$ differs from one, which is usually the normalization done in other studies), which greatly simplified the computations. Next, the model matches consumption-to-output ratio by construction; The investment and government purchases ratios are also closely approximated,

\footnotetext{
${ }^{5}$ In the Appendix, as a robustness check, we perform an alternative calibration procedure
} for $\eta$ and $\theta$. 
Table 1 - Model Parameters

\begin{tabular}{llll}
\hline \hline Parameter & Value & Description & Method \\
\hline$\beta$ & 0.937 & Discount factor & Calibrated \\
$\alpha$ & 0.429 & Capital Share & Data average \\
$1-\alpha$ & 0.571 & Labor Share & Calibrated \\
$\gamma$ & 0.867 & Relative weight attached to leisure & Calibrated \\
$\delta$ & 0.050 & Depreciation rate on physical capital & Data average \\
$\eta$ & 0.670 & Share of working hours used productively & Set/Estimated \\
$\theta$ & 0.867 & Share of evaded VAT revenue & Calibrated \\
$\tau^{y}$ & 0.100 & Average tax rate on income & Data average \\
$\tau^{c}$ & 0.200 & VAT/consumption tax rate & Data average \\
\hline
\end{tabular}

despite the closed-economy assumption and the absence of foreign trade sector. The shares of income are also identical to those in data, which is an artifact of the assumptions imposed on functional form of the aggregate production function. The after-tax return, where $\tilde{r}=\left(1-\tau^{y}\right) r-\delta$ is also relatively well-captured by the model.

Table 2 - Data Averages and Long-run Solution

\begin{tabular}{llll}
\hline \hline Variable & Description & Data & Model \\
\hline$y$ & Steady-state output & $\mathrm{N} / \mathrm{A}$ & 1.000 \\
$c / y$ & Consumption-to-output ratio & 0.674 & 0.674 \\
$i / y$ & Investment-to-output ratio & 0.201 & 0.175 \\
$g^{c} / y$ & Government cons-to-output ratio & 0.159 & 0.151 \\
$w \eta h / y$ & Labor income-to-output ratio & 0.571 & 0.571 \\
$r k / y$ & Capital income-to-output ratio & 0.429 & 0.429 \\
$h$ & Share of time spent working & 0.333 & 0.333 \\
$A$ & Scale parameter of the production function & $\mathrm{N} / \mathrm{A}$ & 1.095 \\
$\tilde{r}$ & After-tax net return on capital & 0.056 & 0.067 \\
$\theta \tau^{c} c / y$ & VAT evasion-to-output ratio & 0.265 & 0.257
\end{tabular}

Next, the model predicts that the magnitude of VAT evasion relative to output is approximately $26 \%$. Using data from the National Revenue Agency, Philip (2014) states that the size of VAT evasion relative to output is 0.265 , or to one-forth of the goods and services sold fiscal receipts have not been issued. This is very close to the European Commission (2014) figure of $25 \%$ as well. According to Boev and Boshnakov (2008), the share of successfully evaded VAT is between 16-35\% on average in the form of turnover tax, while World Bank estimates (in Pashev 2006) amount to one-third of VAT revenue being evaded. Bulgarian tax authorities themselves compute the evasion to be $20-45 \%$ of VAT revenues. Given that VAT makes almost half of total tax revenue, those figures are in line with the model estimates. All across the range, VAT evasion represents a significant loss when compared to aggregate output. 


\section{Policy Experiment}

In this section we will consider a computational experiment, which would correspond to an improvement of institutional quality on the side of the government. In particular, the institutional reform that we will consider is an increase of spending on law and order as a way to decrease the amount of evaded VAT ${ }^{6}$ This would allow to evaluate the welfare effect produced by better policing, holding everything else in the model unchanged. As in Vasilev (2015a), the welfare gain will be represented in the form of a consumption gain, or more specifically, as the additional percentage by which steady-state consumption under the benchmark case needs to be increased to make the household as well off as under the steady-state with increases spending on order and safety. $]^{7}$

Following Angelopoulos et al. (2009), the effective share of the pie (the product of $\theta$ and hours ratio) is now amended to

$$
\theta_{0}=\theta\left(g^{p} / y\right)^{-\epsilon_{2}}\left(\frac{\left(1-\eta_{i t}\right) h_{i t}}{\sum_{i}\left(1-\eta_{i t}\right) h_{i t}}\right)^{\epsilon_{1}},
$$

where $g^{p}$ denotes the new category of public spending - on order and safety - and $g^{p} / y$ is the share of this program in output. parameters $\epsilon_{1}$ and $\epsilon_{2}$ are the shares attached to each of the two components. The negative sign of $\epsilon_{2}$ in the contest function is driven by the fact that more spending on law and order is expected to decrease the amount of evaded VAT. Note that the case $\epsilon_{1}=1, \epsilon_{2}=0$ corresponds to the rent-seeking function used in the benchmark case without any spending on order and safety.

In this extension, we will set $\epsilon_{2}=0.032$, which corresponds to the average share of order and safety in GDP..$^{8}$ The change in the rent-seeking function, and the introduction of a new government spending category will amend the government budget constraint as follows:

$$
g_{t}^{c}+g_{t}^{p}+g_{t}^{t}=(1-\theta) \tau^{c} \sum_{i} c_{i t}+\tau^{y}\left[w_{t} \sum_{i} \eta_{i t} h_{i t}+r_{t} \sum_{i} k_{i t}\right] .
$$

The model needs to be re-calibrated, and the corresponding steady-state with spending on order and safety computed. 9 Note that the new value of

6 The implicit assumption is that a larger spending corresponds to even larger increase in efficiency of VAT collection.

7 Here we focus on the steady-state as we do not have time series data on the efficiency of tax administration enforcement technology. This is what Angelopoulos et al. (2011) do when they evaluate the effect of property rights enforcement.

8 The number is much larger than in most of the old EU member-states, and could be explained as a heritage from the old regime: indeed, most of the Eastern European countries that joined the EU relatively recently have a larger share of public funds that is spent on policing.

9 An interesting result is that the size of VAT evasion-to-output in the baseline case with law and order is twice lower, or $13 \%$. In addition, the welfare gain in consumption terms is a bit more than $5 \%$ relative to the case of zero spending on law and order. 
$g^{c} / y$ was lowered to reflect the breakdown into two categories now. After obtaining the new steady-state under the baseline spending on policing, we would increase the spending on the government function (within a plausible range) to compute the quantitative effect on VAT evasion, and the predicted consumption-based gain to society. The results are documented in Table 3 below. As seen from the table, there are substantial gains, which are comparable in size to the gains computed in Angelopoulos et al. (2009). Thus, a suitable increase in the budget on law and order (coupled with suitable increase in efficiency of law enforcement) could substantially increase welfare by decreasing the losses from VAT evasion.10

\section{Table 3 - Long-run Welfare Gain from Better VAT Collection}

\begin{tabular}{lll}
\hline \hline$g^{p} / y$ & $\theta_{0}=\theta\left(g^{p} / y\right)^{-\varepsilon_{2}}$ & Welfare gain (in \% of additional steady-state consumption) \\
$3.2 \%$ & 0.968 & - \\
$4.0 \%$ & 0.961 & 8.4 \\
$4.8 \%$ & 0.955 & 11.5 \\
$5.6 \%$ & 0.951 & 13.8 \\
\hline
\end{tabular}

\section{Discussion and Model Limitations}

In this section we discuss the mechanics of the model, and some of the potential limitations of the study, some of which due to the simplifying modeling choices implemented in the theoretical setup. The reason why in equilibrium a household would decide to engage in VAT evasion is that the flows of extracted consumption tax revenue are seen as common property resources, and in public-finance setups individual rationality turns out to be sub-optimal from the perspective of society in general. Instead of delving into the source of government inefficiency, the model took as given the authorities' inability to collect all VAT, and proceeded to quantify the aggregate cost of such evasion.

For simplicity, the analysis assumed that only households could engage in VAT evasion, as in neoclassical economics firms are just production sets. Indeed, as mentioned in the introduction, government officials could also be part of such schemes, but solving for a full-blown political economy equilibrium is beyond the scope of this paper. Instead, we decided to focus on tractable exogenous policy experiments, such as the institutional reform that results in an increased VAT collection by the government. In the model, $\theta$, was interpreted as the parameter determining the efficiency of the tax administration, thus more spending on law and order led to a lower size of the

${ }^{10}$ In the Appendix, we perform a sensitivity analysis to investigate how the results change under alternative calibration for the two parameters associated with VAT evasion, $\eta$ and $\theta$. 
pie, and a lower share of lost tax revenues. Lowering $\theta$ in turn lowers the incentive to engage in tax evasion, hence $\eta$, the share of working time spent at the firm, increases.

Another policy implication that can be drawn from this model is that if $\tau^{c}$ is lowered, that would also lower the prize. Differentiation of the tax rate, e.g., having a lower tax on food and books, could be one such solution. Still, this could trigger other forms of VAT fraud, unless such reforms are complemented with better transparency in transactions. ${ }^{11}$ The fact that almost half of the tax revenue comes from VAT, makes governments unwilling to change the rate, as in that way they would lose a substantial amount of revenue. After all, consumption tax is an example of a tax on demand, and consumption spending is the largest part of aggregate demand.

Lastly, local tax authorities could introduce an information campaign, and urge people to collect their receipts. ${ }^{12}$ In other words, instead of playing the non-cooperative Nash equilibrium strategy, which results in a negativesum repeated game, the government can inform the households that they are playing against each other, and thus they should behave cooperatively (which leads to a zero-sum game). This would lead to no VAT evasion in equilibrium, and all time will be spent working in the firm, $\eta_{t}=1$ for all $t^{13}$

\section{Conclusions}

This paper uses modern quantitative macroeconomic theory to estimate the size of the loss from the VAT evasion at aggregate level, and we focus on the period following the introduction of the currency board in 1997. The setup is a micro-founded framework populated by a unit mass of households and augmented with a revenue-extraction mechanism as in Vasilev (2017). Similarly to Angelopoulos et al. (2009, 2011), each one-member household can decide to spend working time on rent-seeking activities and try to hide (or equivalently, "extract") part of the VAT revenue from the government. The model was calibrated to Bulgaria, as one of the few countries in Europe (and the only one in the EU) with a non-differentiated consumption tax rate, and where VAT revenue makes almost half of total government tax revenue. Using models that are disciplined by both theory and

\footnotetext{
${ }^{11}$ Some potential anti-fraud measures include the VAT account, and the so-called indicative "market" prices of commercial transactions; Multi-phase credit schemes have also been proposed. Yet another idea that has been circulated by economists is the harmonization of tax rates, and integration of tax offices of EU countries, as part of the fiscal integration. However, a detailed discussion of those is beyond the scope of this paper. The interested reader should consult Pashev (2006) and the references therein.

12 This is what the National Revenue Agency is trying to achieve in its most recent campaign (2015-16): receipts collected can be mailed to participate in lotteries with prizes like smart phones, TV sets, even a car.

${ }^{13}$ Such an outcome, though in a slightly different setup, is predicted also in Angelopoulos et al. (2009). It is not clear whether such a trigger strategy is sustainable or not.
} 
data provides a useful tool to inform policy makers on issues, whose effects are otherwise hard to measure. For example, a computational experiment was performed, which estimated the size of evaded VAT to be a bit more than one-fourth of output, a number which is in line with figures provided in both Philip (2014) and the European Commission (2014). Policy experiments based on the model show that suitable increases in spending on law and order (coupled with suitable increase in efficiency of law enforcement) could generate substantial welfare gains by decreasing the losses from VAT evasion. 


\section{References}

Angelopoulos, K., Economides, G., Vassilatos, V., 2011. Do Institutions Matter for Economic Fluctuations? Weak Property Rights in a Business Cycle Model for Mexico. Review of Economic Dynamics 14, 511-531.

Angelopoulos, K., Philippopoulos, A., Vassilatos, V., 2009. The Social Cost of Rent-Seeking in Europe. European Journal of Political Economy 25, 280299.

Alvarez-Martinez, M., Polo, C., 2014. A General Equilibrium Evaluation of Tax Policies in Spain During the Great Depression. Revista de Economia Aplicada 65, 99-115.

Boev, V., Boshnakov, V., 2008. Grey Economy and Corruption in Bulgaria: Empirical Evidence. Proceedings from the 4th International Conference "Development: Cooperation and Competitiveness", 22-24 May, Bucharest, Romania.

Bulgarian National Bank 2015. Bulgarian National Bank Statistics. Available on-line at www.bnb.bg. Accessed on Oct. 21, 2015.

Bye B., Strom, B., Avitsland, B., 2015. Welfare Effects of VAT Reforms: A General Equilibrium Analysis. Central Bank of Norway, Mimeo.

Center for the Study of Democracy 2015. Hidden Economy Indexes in Bulgaria 2002-2015: Results and Methodological Notes, Sofia, Bulgaria.

De Melo, J., Roland-Holst D., Haddad, M., 1992. Tax Evasion and Tax Reform in a Low-Income Economy: General-Equilibrium Estimates for Madagascar. World Bank Policy Paper 918, Washington DC.

European Commission 2014. Special Eurobarometer 402: Undeclared Work, Brussels: European Commission.

Kehoe, T. J., Noyola, P.J., Mandresa, A., Polo, C., Sancho, F., 1988. A General Equilibrium Analysis of the 1986 Tax Reform in Spain. European Economic Review 32, 334-342.

National Statistical Institute 2015. Aggregate Statistical Indicators. Available on-line at www.nsi.bg. Accessed on Oct. 21, 2015.

Pashev, K., 2006. Fighting VAT Fraud: The Bulgarian Experience. Center for the Study of Democracy Working paper 0606/2, Sofia, Bulgaria.

Philip, L.R., 2014. The Grey Economy of Post-communist New EU Member States: Case of Bulgaria. Horizons of Politics 5, 91-112. 
Vasilev, A., 2015a. The Flat Tax Reform in Bulgaria and the Size of the Informal Sector. Economic Change and Restructuring 48, 169-185.

Vasilev, A., 2015b. Welfare Effects of Flat Income Tax Reform: The Case of Bulgaria. Eastern European Economics 53, 205-220.

Vasilev, A., 2017. On the cost of Opportunistic Behavior in the Public Sector: A General-Equilibrium Approach. Journal of Public Economic Theory 19, 565-582.

WDI 2015. World Development Indicators. Available on-line at www.worldbank.org/data/wdi. Accessed on Oct. 21, 2015.

\section{Appendix: Sensitivity Analysis}

In this appendix we perform an alternative calibration for $\eta$, the proportion of time spend on productive labor, to see how the quantitative and the qualitative results in the model are affected. As an extreme case, we follow Angelopoulos et. al. (2009) and set $\eta=0.88$, which corresponds to the average value obtained for the EU-12 countries. In other words, we compute the size of VAT evasion for a hypothetical scenario for Bulgaria, in which Bulgaria has achieved a level of institutional efficiency equal to one in EU-12. The results in Table 4 below show that in such a scenario the VAT evasion parameter would decrease to almost a third of the initial value, $\theta=0.312$. In turn, the size of evaded VAT relative to output would go down to $17 \%$.

Table A.1 - Data Averages and Long-run Solution

\begin{tabular}{llll}
\hline \hline Variable & Description & Data & Model \\
\hline$y$ & Steady-state output & $\mathrm{N} / \mathrm{A}$ & 1.000 \\
$c / y$ & Consumption-to-output ratio & 0.674 & 0.674 \\
$i / y$ & Investment-to-output ratio & 0.201 & 0.175 \\
$g^{c} / y$ & Government cons-to-output ratio & 0.159 & 0.227 \\
$w \eta h / y$ & Labor income-to-output ratio & 0.571 & 0.571 \\
$r k / y$ & Capital income-to-output ratio & 0.429 & 0.429 \\
$h$ & Share of time spent working & 0.333 & 0.333 \\
$A$ & Scale parameter of the production function & $\mathrm{N} / \mathrm{A}$ & 1.095 \\
$\tilde{r}$ & After-tax net return on capital & 0.056 & 0.067 \\
$\theta \tau^{c} c / y$ & VAT evasion-to-output ratio & 0.265 & 0.166
\end{tabular}


Next, we perform the same fiscal policy experiment described in section 5 , but under the alternative calibration for the VAT evasion parameters presented above, namely $\eta=0.88$, and $\theta=0.312$. With only a third of consumption revenue being lost by the government, the gains from increased spending on police are larger, as there are lower inefficiencies in the model economy, a higher proportion of total time is used productively, and thus there is more production, and thus higher consumption and investment, and more resources are available for both government transfers and valuable public services. In other words, there is a substantial complementarity between a higher institutional quality (lower evasion) and more spending on improving VAT collection (by hiring more tax inspectors, etc). Furthermore, as a result, there is double-digit consumption-equivalent welfare gain from increasing spending on VAT collection improvement, and depending on the magnitude of the expansion in the share of spending on policing, households' welfare increases by $11-16.6 \%$ in the long-run.

Table A.2 - Long-run Welfare Gain from Better VAT Collection

\begin{tabular}{lll}
\hline \hline$g^{p} / y$ & $\theta_{0}=\theta\left(g^{p} / y\right)^{-\varepsilon_{2}}$ & Welfare gain (in \% of additional steady-state consumption) \\
$3.2 \%$ & 0.348 & - \\
$4.0 \%$ & 0.341 & 11.18 \\
$4.8 \%$ & 0.334 & 14.27 \\
$5.6 \%$ & 0.329 & 16.58
\end{tabular}

